\title{
Repercussões dos períodos anteriores $e$ simultâneos ao acolhimento institucional
}

\author{
Repercussions of prior and simultaneous periods to institutional reception
}

\section{Jessica Koslowski Tejada e Ingrid D'Avila Francke ${ }^{2}$}

\begin{abstract}
Resumo: $O$ estudo em questão busca conhecer as contingências que perpassam os períodos anteriores e simultâneos às institucionalizações e as discussões do impacto destas variáveis sobre o desenvolvimento das crianças e adolescentes em situação de acolhimento institucional. Trata-se de uma revisão sistemática da literatura de análise qualitativa e as buscas foram realizadas nos bancos de dados eletrônicos do Portal de periódicos CAPES e da Biblioteca Virtual em Saúde (BVS), utilizando-se de exaustivas estratégias de busca com descritores e operadores booleanos congruentes com os objetivos da pesquisa. Os resultados demonstram que tanto no ambiente familiar, quanto nas instituições de acolhimento, não houveram contingências favoráveis ao desenvolvimento saudável destes indivíduos. Verifica-se a importância do planejamento de ações voltadas às famílias de origem e às instituições de acolhimento, que levem a atuações e cuidados que protejam, promovam e estimulem o desenvolvimento saudável. A manutenção da sobrevivência destes indivíduos deve ser modificada para uma prática de cuidados protetivos e promotores de desenvolvimento positivo, sendo a psicologia instrumento de análise e planejamento de ações em prol das crianças e adolescentes.
\end{abstract}

Palavras-chave: Desenvolvimento; Acolhimento institucional; Crianças e adolescentes.
Abstract: The study in question seeks to understand the contingencies that pervade the periods prior and simultaneous to institutionalization and the discussions on the impact of these variables on the development of children and adolescents in institutional care situations. This is a systematic literature review of qualitative analysis and searches were performed in the electronic databases of the CAPES Journal Portal and the Virtual Health Library $(\mathrm{VHL})$, using exhaustive search strategies with Boolean descriptors and operators congruent with the research objectives. The results demonstrate that both in the family environment and in the care institutions, there were no contingencies favorable to the healthy development of these individuals. It is important to plan actions aimed at families of origin and host institutions, which lead to actions and care that protect, promote and encourage healthy development. The maintenance of the survival of these individuals must be modified to a practice of protective care and promoters of positive development, with psychology being an instrument for analyzing and planning actions in favor of children and adolescents.

Keywords: Development; Institutional reception; Children and adolescents.

\footnotetext{
1 Psicóloga pela Universidade Luterana do Brasil - ULBRA. E-mail: jessika.k.t@rede.ulbra.br

2 Psicóloga. Doutora em Saúde Coletiva. Professora da ULBRA. E-mail: ingrid.francke@ulbra.br
} 


\section{Introdução}

0 Estatuto da Criança e Adolescente (ECA), através da Lei № 8.069, considera como criança, a pessoa com até doze anos incompletos, e adolescente aquele com idade entre doze e dezoito anos. Este estatuto traz um conjunto de normas que garantem a estes sujeitos 0 direito ao pleno desenvolvimento físico, mental, moral, espiritual e social (Brasil, 1990).

A família ocupa papel central no desenvolvimento humano, exercendo tradicionalmente funçoes que envolvem aspectos biológicos, psicológicos e sociais, sendo contexto primário de desenvolvimento do ser humano (Zappe \& Dell'Aglio, 2016). Conforme Vasconcellos e Koehler (2011) a infância é uma etapa importante no desenvolvimento, onde as relações estabelecidas entre a criança e a família refletem sobre a formação da identidade e as relações e vínculos mantidos com as demais pessoas ao longo do tempo.

Em conformidade, a legislação brasileira reconhece a família como espaço ideal e privilegiado para o desenvolvimento, devendo ser lugar essencial à humanização e à socialização da criança e do adolescente. № entanto, percebe-se através da história que muitas famílias encontram inúmeras dificuldades para proteger e educar seus filhos, sendo necessária a intervenção por parte do Poder Público (Brasil, 2006). Neste sentido, estes devem ser levados provisoriamente a programas de acolhimento, cabendo a instituição agir como substituto provisório para a família, protegendo e apoiando estes indivíduos (Brasil, 1990).

Não obstante, o positivo desenvolvimento emocional, cognitivo e social do indivíduo, dependem da continuidade dos cuidados afetivos que recebem. Contudo, nem sempre 0 ambiente de acolhimento fornece às crianças e adolescentes todos os direitos previstos, seja por questões como superlotação de órgãos públicos, falta de preparo profissional ou falta de recursos. No entanto, em muitos casos 0 acolhimento é capaz de proporcionar um espaço seguro e protetivo, com benefícios ligados ao relacionamento interpessoal, desempenho escolar e comportamentos agressivos (Bianchin \& Gomes, 2018).

Em concordância, os autores Cavalcante e cols. (2014) concluíram em seu estudo que a vivência em meio à desagregação familiar, violência e drogadição podem levar a alterações no desenvolvimento, impactando sobre os aspectos sociais, cognitivos e afetivos e na formação da identidade. Estes mesmos autores relatam que, da mesma forma, condições desfavoráveis de experiência e cuidado institucional podem causar tais prejuízos.

Diante do exposto, entende-se que levar este tema à discussão acadêmica/científica seja de extrema relevância, podendo levar a compreensão do estado da arte sobre as contingências que cercam o processo de acolhimento e institucionalização de crianças e adolescentes. Não obstante, compreender tais aspectos possibilita o planejamento de ações que ajam como protetoras para o desenvolvimento saudável destes indivíduos. Outrossim, espera-se conhecer as contingências que perpassam os períodos anteriores e simultâneos às institucionalizações e as discussões do impacto destas variáveis sobre 0 desenvolvimento das crianças e adolescentes em situação de acolhimento.

\section{Método}

Este estudo trata de uma revisão sistemática de análise qualitativa de estudos primários, onde as buscas foram realizadas nos bancos de dados eletrônicos do Portal de periódicos CAPES e Biblioteca Virtual em Saúde (BVS), utilizando como estratégia de busca os descritores "criança AND acolhimento institucional AND desenvolvimento infantil".

Os critérios de inclusão foram artigos publicados nos últimos dez anos, compreendendo o período de 2009 a 2019, bem como periódicos revisados por pares e em língua portuguesa, inglesa e espanhola para o Portal Capes. Através dos critérios de exclusão, foram desconsiderados estudos que abarcavam indivíduos que não tenham passado pelo processo de acolhimento institucional, aspectos ou fatores ambientais que não aludem a questões desenvolvimentais, adoção e período pós institucionalização, crianças e adolescentes com deficiência intelectual e/ou transtorno mental, artigos duplicados e estudos de revisão.

A Figura 1 mostra o processo de seleção dos artigos em suas diferentes etapas e o respectivo número de artigos recuperados em cada uma.

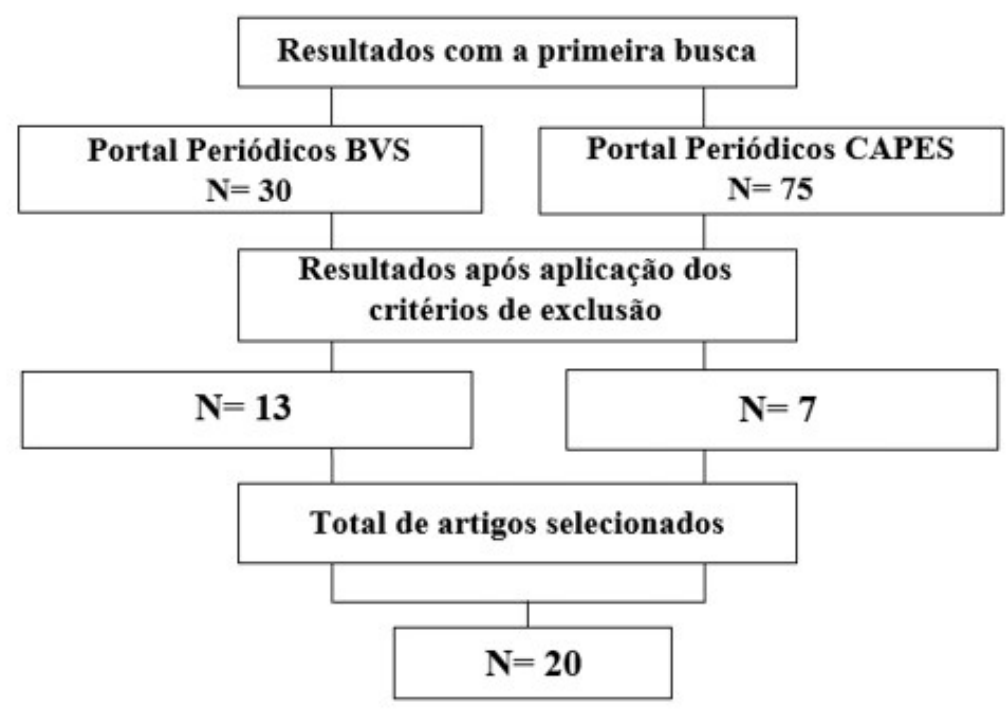

Figura 1 - Fluxograma do método de busca. 


\section{Resultados e discussão}

Tabela 1 - Estudos compatíveis com a pesquisa.

\begin{tabular}{|c|c|c|c|}
\hline Autores/ano & Título & Amostra & Principais resultados \\
\hline Avoglia e cols. (2012) & $\begin{array}{l}\text { Educador social: Imagem e relações com crianças em situação de } \\
\text { acolhimento institucional }\end{array}$ & 6 educadoras & $\begin{array}{l}\text { Ausência de contato afetivo, concepção de lugar inapropriado para } 0 \\
\text { desenvolvimento. }\end{array}$ \\
\hline Both e Benetti (2017) & $\begin{array}{l}\text { As representações parentais em crianças institucionalizadas filhos } \\
\text { de usuária de crack }\end{array}$ & 3 irmãos & $\begin{array}{l}\text { Representações mentais negativas, ambiente desestruturado e } \\
\text { negligente. }\end{array}$ \\
\hline Cavalcante e cols. (2014) & $\begin{array}{l}\text { Análise Comparativa do Perfil de Crianças em Acolhimento Insti- } \\
\text { tucional nos Anos de } 2004 \text { e } 2009\end{array}$ & 287 crianças & $\begin{array}{l}\text { Maior índice de pobreza do que os encontrados na população geral. } \\
\text { Aumento do tempo em que as crianças se mantiveram atendidas } \\
\text { pelo serviçco. }\end{array}$ \\
\hline Corrêa e Cavalcante (2013) & $\begin{array}{l}\text { Shelter educators: conceptions on development and care practices } \\
\text { in play situation }\end{array}$ & 100 educadores & 66\% dos educadores acertaram em média 66 questões. \\
\hline Cruz e cols. (2014) & $\begin{array}{l}\text { Estudo do "Ages and Stages Questionnaires" com cuidadores de } \\
\text { crianças institucionalizadas }\end{array}$ & $\begin{array}{l}4 \text { crianças } 4 \text { cui- } \\
\text { dadoras }\end{array}$ & Alterações na comunicação. \\
\hline Dias e cols. (2015) & $\begin{array}{l}\text { Avaliação de Desenvolvimento de Bebês em Acolhimento Institu- } \\
\text { cional com "Ages and Stages Questionnaires" }\end{array}$ & 6 bebês & Alterações no desenvolvimento. \\
\hline Franco e cols. (2014) & Linguagem receptiva e expressiva de crianças institucionalizadas & 30 crianças & Não houve diferença significativa. \\
\hline Golin e Benetti (2013) & Acolhimento Precoce e o Vínculo na Institucionalização & 3 meninos & Distorções importantes no estabelecimento de vínculos. \\
\hline Gontijo e cols. (2012) & $\begin{array}{l}\text { Fatores relacionados à institucionalização de crianças e adolescentes } \\
\text { acolhidos na comarca de Uberaba - MG }\end{array}$ & 169 crianças & $\begin{array}{l}\text { Somente } 24 \% \text { das crianças em idade escolar tinham escolaridade } \\
\text { adequada à faixa etária. }\end{array}$ \\
\hline Guerra e Del Prette (2018) & $\begin{array}{l}\text { Habilidades sociais educativas de cuidadores de crianças insti- } \\
\text { tucionalizadas }\end{array}$ & $\begin{array}{l}36 \text { crianças e } 19 \\
\text { cuidadores }\end{array}$ & Cuidadores: habilidades sociais educativas abaixo da norma. \\
\hline $\begin{array}{l}\text { Heumann e Cavalcante } \\
\text { (2018) }\end{array}$ & $\begin{array}{l}\text { Rotinas de crianças e adolescentes em acolhimento institucional: } \\
\text { estudo descritivo }\end{array}$ & 18 profissionais & Principais atividades: Sono, descanso ou despertar. \\
\hline Maciel e cols. (2017) & $\begin{array}{l}\text { Crianças à espera de adoção ou em medida protetiva: a inclusão } \\
\text { escolar }\end{array}$ & 10 crianças & Problemas na integração das crianças na escola. \\
\hline Misquiatti e cols. (2015) & $\begin{array}{l}\text { Desempenho de vocabulário em crianças pré-escolares institu- } \\
\text { cionalizadas }\end{array}$ & 48 crianças & Desempenho inferior na prova de vocabulário. \\
\hline Paiva e cols. (2019) & $\begin{array}{l}\text { Acolhimento Institucional: famílias de origem e a reinstitucio- } \\
\text { nalização }\end{array}$ & $81 \mathrm{G} . \mathrm{A}$. & Pobreza e ausência de Acompanhamento das famílias. \\
\hline Pereira e cols. (2010) & $\begin{array}{l}\text { Desenvolvimento, psicopatologia e apego: estudo exploratório com } \\
\text { crianças institucionalizadas e suas cuidadoras }\end{array}$ & 16 crianças & $\begin{array}{l}\text { Nível de desenvolvimento inferior, sintomas de internalização e } \\
\text { externalização. }\end{array}$ \\
\hline Sá e cols. (2017) & $\begin{array}{l}\text { Desenvolvimento infantil e } 0 \text { ambiente institucional - experiência } \\
\text { com bebês abrigados }\end{array}$ & $\begin{array}{l}\text { Estudantes de } 5 \\
\text { cursos }\end{array}$ & $\begin{array}{l}\text { Cuidados voltados às necessidades básicas, executados de forma rápida } \\
\text { e mecânica. }\end{array}$ \\
\hline Silva e cols. (2014) & Interações entre avós e netos em instituição de acolhimento infantil & 31 crianças & $22 \%$ das crianças estava fora da escola. \\
\hline Silveira e cols. (2016) & $\begin{array}{l}\text { Condição nutricional de crianças admitidas em uma instituição } \\
\text { de acolhimento }\end{array}$ & 166 crianças & 78\% das crianças chegaram eutróficas à instituição. \\
\hline Siqueira e Dell'Aglio (2010) & $\begin{array}{l}\text { Crianças e Adolescentes Institucionalizados: Desempenho Escolar, } \\
\text { Satisfação de Vida e Rede de Apoio Social }\end{array}$ & 155 acolhidos & Baixo desempenho escolar e alto índice de repetência. \\
\hline Tomás e Vectore (2012) & $\begin{array}{l}\text { Perfil Mediacional de Mães Sociais que Atuam em Instituiç̧̃es } \\
\text { de Acolhimento }\end{array}$ & 4 mães sociais & Distanciamento afetivo e falta de capacitação dos profissionais. \\
\hline
\end{tabular}

Os artigos identificados pela estratégia de busca inicial ( $N=105)$ foram avaliados e após a leitura dos resumos foram aplicados os critérios de exclusão. Este processo resultou na seleção de 20 artigos, conforme Tabela 1, sendo 17 artigos em língua portuguesa, 2 em língua inglesa e 1 em língua espanhola.

Após a leitura dos 20 artigos elegíveis, a análise e discussão dos resultados, segundo os objetivos deste estudo, resultaram em duas categorias temáticas: contexto familiar e contexto de acolhimento institucional.

\section{Contexto familiar}

Embora seja desejável, nem sempre 0 ambiente familiar age de forma protetora e propícia ao desenvolvimento saudável das crianças e adolescentes. Neste sentido, os motivos que justificam o acolhimento, são aspectos que têm efeito negativo sobre o desenvolvimento do indivíduo (Cavalcante, Magalhães \& Reis, 2014). As pesquisas concordam que dentre os motivos mais frequentes para 0 acolhimento institucional, encontra-se a negligência familiar, 0 abandono, dependência de álcool e outras drogas por parte dos pais e/ou responsáveis, a violência física e sexual no ambiente doméstico e a precariedade das condições socioeconômicas, como a pobreza (Cavalcante 
\& cols., 2014; Gontijo, Buiati, Santos \& Ferreira, 2012; Paiva, Moreira \& Lima, 2019; Pereira \& cols., 2010; Silva, Magalhães \& Cavalcante, 2014; Silveira, Costa, Pinho \& Santana, 2016; Siqueira \& Dell'Aglio, 2010).

Alguns pesquisadores afirmam que as condições socioeconômicas das famílias eram iguais ou mais graves que a situação da maioria das famílias brasileiras, com rendimentos iguais ou inferiores ao salário mínimo vigente (Cavalcante \& cols., 2014; Gontijo \& cols., 2012). Os autores aqui citados relatam que as crianças não recebiam os cuidados adequados e viviam em grande vulnerabilidade social, bem como residiam nos locais com maiores índices de violência e desigualdade social (Paiva \& cols., 2019), e apresentavam condições precárias de nutrição, higiene e saúde, fatores que representam risco ao desenvolvimento nos anos iniciais (Cavalcante \& cols., 2014; Dias, Pedroso \& Santos, 2015). A pobreza traz consigo fatores como a falta de acesso a serviços de saúde, alimentação adequada, questões ligadas à higiene pessoal, e outros diversos aspectos que podem acarretar em alterações desenvolvimentais.

No que concerne a nutrição, o estudo de Silveira e cols. (2016), mostrou que embora 78\% das crianças estivessem com nutrição de boa qualidade no momento da admissão na instituição de acolhimento, 12\% da amostra apresentou baixa estatura, 9,6\% apresentou baixo peso por idade, 7,2\% apresentou desnutrição segundo os índices de peso por estatura e $9 \%$ apresentou desnutrição segundo os índices de massa corporal. Os índices apresentados no estudo eram maiores do que as médias da população infantil do Estado de Pernambuco, segundo os pesquisadores. 0 estado nutricional destes indivíduos pode afetar diversas áreas do desenvolvimento e pode estar ligado às condições socioeconômicas das famílias, e em alguns casos, a negligência de cuidados. Cabe destacar que segundo o Estatuto da Criança e Adolescente, é direito desses sujeitos serem criados em ambiente que garanta seu desenvolvimento integral (Brasil, 1990), onde nem sempre a família de origem tem garantido estes direitos, cabendo ao Estado intervir em favor dos menores.

Ressalta-se que além da privação material, a pobreza pode trazer consigo a privação emocional e social, atingindo as crianças no período de maior sensibilidade em termos de desenvolvimento (Cavalcante \& cols., 2014). Neste sentido, os pesquisadores Both e Benetti (2017), verificaram que as crianças acolhidas apresentaram representações mentais negativas dos pais e diversos sintomas e comportamentos disfuncionais indicativos de um ambiente desestruturado para o desenvolvimento mental, onde prevaleceu a negligência de cuidados e afetos.

0 acesso à educação e a todo progresso advindo deste ambiente é um fator importante a ser considerado, no que se refere a aspectos intelectuais e sociais. Uma pesquisa apontou que apenas $48 \%$ das crianças e adolescentes em idade escolar frequentavam a escola antes do acolhimento (Gontijo \& cols., 2012), somente 64\% dos participantes nunca abandonaram a escola no período anterior à institucionalização (Siqueira \& Dell'Aglio, 2010), e grande parte deles não possuía escolaridade adequada a sua idade (Gontijo \& cols., 2012; Siqueira \& Dell'Aglio, 2010). Além disso, os participantes apresentaram resultados com baixos escores no Teste de Desempenho Escolar (Siqueira \& Dell'Aglio, 2010). Tais dados demonstram que 0 ambiente familiar não foi capaz de garantir o direito à educação a estes indivíduos.

0 uso de drogas por parte dos pais é considerado por muitos autores como um fator agravante para as alterações no desenvolvimento. Os pesquisadores Golin e Benetti (2013) e Both e Benetti (2017) identificaram uma parcela significativa de pais que faziam uso de drogas, assim como histórico de abandono e negligência. Na pesquisa realizada por Both e Benetti (2017), os pesquisadores apontam o uso do crack no período intrauterino por parte da mãe como um provável causador dos comportamentos disfuncionais apresentados pelos três irmãos participantes da pesquisa. Estes indivíduos apresentaram comportamentos agressivos e fantasiosos, sentimento de insegurança, depreciação, incompetência, ansiedade, imaturidade, retraimento e impulsividade. As representações parentais eram punitivas e ineficazes, com pouca afetividade. De modo geral as crianças não se apresentaram como sujeitos saudáveis, demonstrando ego desorganizado e apresentando problemas de ordem afetiva, comportamental e social.

Além disso, o fato de a mãe ser usuária de drogas pode ter causado cuidados inapropriados às crianças, como se verifica no estudo de Dias e cols. (2015) onde cinco das seis crianças, apresentaram alterações desenvolvimentais na coordenação motora ampla e fina, resolução de problemas, estabelecimento de relações e comunicação. Embora não tenha sido comprovado o uso de drogas durante o período intrauterino neste último estudo, a condição de usuária das mães pode ter significativo papel nos atrasos desenvolvimentais, devido a negligência de cuidados e falta de estímulos.

Além das alterações já apresentadas, al gumas crianças institucionalizadas apresentaram comportamento e interesse sexual precoce, onde o histórico acusou suspeita de abuso sexual, bem como houve exposição a comportamentos impróprios à idade (Both \& Benetti, 2017; Cruz, Dias \& Pedroso, 2014). Énítido que em muitos casos, os ambientes em que viviam as crianças e adolescentes além de negligentes, propiciavam a violação das crianças de diversas formas, afetando sua integridade física, psicológica e social.

\section{Contexto de acolhimento institucional}

A idade dos indivíduos que se encontram em situação de acolhimento institucional é importante para a avaliação dos prejuízos para o desenvolvimento. Alguns estudos demonstram que ao longo dos anos um número expressivo de crianças é exposto aos efeitos da institucionalização ainda na primeira infância, em faixas etárias de zero a três anos, período este crítico para o desenvolvimento infantil (Cavalcante \& cols., 2014). Os dados demonstram que em instituições responsáveis pelo acolhimento de crianças até seis anos de idade, mais de 45\% das crianças tinham idade de no máximo 12 meses (Silva \& cols., 2014; Silveira \& cols., 2016). Já em instituiç̧ões de acolhimento para crianças e adolescentes, Gontijo e cols. (2012) referem que 34\% dos indivíduos acolhidos eram adolescentes acima de 12 anos de idade. Esta faixa etária permanece mais tempo nas instituições devido à inserção em família substituta ser mais difícil, pela preferência dos candidatos à adoção por crianças de até três anos de idade.

Em conformidade, o longo tempo de permanência em ambiente de acoIhimento é um fator recorrente, onde os tempos médios de institucionalização ultrapassaram os 2 anos (Cavalcante \& cols., 2014; Gontijo \& cols., 2012; Pereira \& cols., 2010; Siqueira \& Dell'Aglio, 2010), e alguns indivíduos chegavam a estar na instituição por um período de até 12 anos (Siqueira \& Dell'Aglio, 2010). Estes dados contrariam o direito à família previsto pelo ECA, onde 0 Estado deve garantir a reintegração ou a substituição da família. Além disso, o tempo de permanência no programa de acolhimento não deve ultrapassar 1 ano e 6 meses, salvo casos especiais (Brasil, 1990). 0 caráter provisório da medida de acolhimento não tem sido cumprido, levando a reflexão do que seriam os casos especiais de que trata este estatuto, e que acabam por ser comumente encontrados. 
A pesquisa realizada por Siqueira e Dell'Aglio (2010), ressalta os prejuízos do longo tempo de permanência nestes locais. Os pesquisadores identificaram que embora a instituição de acolhimento tenha sido o campo que apresentou maior quantidade de relacionamentos de grande proximidade, quanto maior o tempo de institucionalização, menor foi a média de contatos, de proximidade destes contatos e da satisfação de vida, influenciando a rede de apoio destes indivíduos e a qualidade das relações estabelecidas. Além disso, 0 distanciamento afetivo e o menor investimento nas relações interpessoais, conforme os autores, agem como mecanismo de defesa para aspectos como a rotatividade dos funcionários na instituição e o desligamento dos demais acolhidos. É provável que as relações futuras destas crianças e adolescentes sejam afetadas pela insegurança diante das relações e o medo da separação.

Em relação aos contatos estabelecidos e aos cuidados nas instituições de acolhimento, verifica-se que existe uma precariedade de vínculos afetivos e de investimento no desenvolvimento, onde o grande número de crianças compromete 0 cuidado individual e a resposta às necessidades, causando cuidados mecânicos e rápidos (Sá, Jurdi \& Panciera, 2017). Além disso, a rotina nestes espaços é composta por atividades relacionadas aos cuidados básicos, como alimentação, sono e higiene pessoal, tendo pouco tempo destinado ao lazer e brincadeiras (Heumann \& Cavalcante, 2018; Sá \& cols., 2017). Além disso, verificou-se pouquíssima diferença entre a rotina das crianças e dos adolescentes, com padrões rígidos e repetitivos de funcionamento, oferecendo um número reduzido de estímulos e oportunidades de atividades promotoras de um desenvolvimento positivo (Heumann \& (avalcante, 2018), onde os momentos de falas compartilhadas e vínculos afetivos eram praticamente inexistentes (Tomás \& Vectore, 2012).

Neste mesmo sentido, a pesquisa realizada por Golin e Benetti (2013) evidenciou que as crianças tinham como fortes demandas psicológicas a maior constância nos cuidados, mostrando-se ativas na procura de uma figura de apego com cuidados estáveis e sensíveis. Elas mostravam-se irritadas e tristes, com comportamentos associados ao quadro de Transtorno de Apego, evidenciando um ambiente institucional que não permitia o desenvolvimento de vínculo com interações próximas e previsíveis, com claro distanciamento afetivo, revelando a fragilidade dos cuidados neste espaço.

Outro aspecto muito comum nas instituições é o medo apresentado pelos profissionais de estabelecer víncul os afetivos com os institucionalizados, devido à possibilidade de rompimento (Golin \& Benetti, 2013; Tomás \&Vectore, 2012). Este aspecto, além de atrapalhar a vinculação e o apoio emocional dado às crianças e adolescentes, leva a dificuldades em assumir o papel da família, seja no cuidado diário ou na participação na escola (Maciel, Teodoro, Alves, Ribeiro \& Serralha, 2017).

0 Art. 92 do Estatuto da Criança e Adolescente estabelece que à criança de 0 a 3 anos de idade, em acolhimento institucional, se dará especial atenção à atuação de educadores no atendimento das necessidades básicas, incluindo as de afeto como prioritárias (Brasil, 1990). Tal aspecto retoma a importância dos primeiros anos de vida para o desenvolvimento, embora a realidade apresentada nas pesquisas não seja adequada. Reflete-se ainda a ênfase dada ao atendimento afetivo de crianças até 3 anos de idade, quando esta é uma necessidade de todos os indivíduos, principalmente considerando que a formação da personalidade se dá também durante a adolescência. Outro direito que acaba por não ser concretizado, segundo as pesquisas, é 0 "atendimento personalizado e em pequenos grupos" (Brasil, 1990), onde claramente o número elevado de acolhidos dificulta os cuidados.
A falta de preparo dos cuidadores foi considerada um fator que pode influenciar no desenvolvimento, já que eles apresentaram sentimento de insegurança, postura tensa e controladora e afastamento físico e afetivo das crianças e adolescentes, além de terem demonstrado sintomas de cansaço, esgotamento, falta de ânimo, baixo nível de energia e exaustão emocional (Avoglia, Silva \& Mattos, 2012). A falta de capacitação dos cuidadores gera um desempenho de função com interações medíocres e empobrecidas (Tomás \& Vectore, 2012), onde eles próprios percebem a instituição como um local provisório, que não favorece o desenvolvimento (Avoglia \& cols., 2012; Tomás \& Vectore, 2012), levando a se eximirem do compromisso de educar e promover 0 desenvolvimento (Avoglia \& cols., 2012).

A pesquisa realizada por Corrêa e Cavalcante (2013), evidenciou que 66\% dos cuidadores apresentaram um conhecimento satisfatório sobre 0 Desenvolvimento Infantil, onde aqueles que possuíam maior conhecimento, acabavam por apresentar características de atuação que estimulavam, orientavam e promoviam o desenvolvimento saudável. Considera-se insuficiente o conhecimento apresentado, onde mais de 30\% dos cuidadores não alcançaram um nível satisfatório, levando a reflexão do impacto que a atuação destes profissionais pode causar na vida destes indivíduos. Verifica-se que 0 conhecimento do desenvolvimento infantil pode estar diretamente ligado à compressão do papel destes profissionais como promotores deste processo. Neste sentido, a pesquisa de Cruz e cols. (2014), demonstrou que muitos cuidadores não percebiam as dificuldades desenvolvimentais apresentadas pelas crianças, sendo um agravante para tais problemas, onde acabavam por não receber 0 apoio necessário para se desenvolverem e alcançarem os padrões normativos.

Quanto ao direito à educação, nas instituições de acolhimento também são encontrados alguns problemas que podem interferir no desenvolvimento intelectual e social destes indivíduos. A pesquisa realizada por Silva e cols. (2014) constatou que 22\% das crianças e adolescentes estavam fora da escola no momento da coleta de dados, embora possuíssem idade escolar. Além disso, metade das crianças participantes da pesquisa de Maciel e cols. (2017) sofreu mudança de escola após a entrada na instituição de acolhimento, devido a facilitação do transporte, o que gera distanciamento também dos amigos e colegas aos quais costumavam conviver. Além de serem afastadas de suas famílias, as crianças e adolescentes são retiradas de seu meio social e afastadas de tudo o que the é conhecido. Tal aspecto, objeta o que é previsto pelo ECA, onde 0 acolhimento deverá se dar no local mais próximo à residência natural e a participação na vida da comunidade local também deve ser garantida, dando a eles o direito ao desenvolvimento social (Brasil, 1990).

Ainda sobre as dificuldades no ambiente escolar, a pesquisa realizada por Maciel e cols. (2017) constatou que havia rotulação e discriminação das crianças e adolescentes acolhidos, o que tende a gerar prejuízos de cunho pessoal e dificultar a adaptação ao ambiente escolar. Segundo os autores, os acolhidos apresentavam dificuldades de se relacionar e se vincular com novas pessoas, onde tendiam a se relacionar entre eles mesmos, além de características como carência afetiva, insegurança, defasagem de aprendizagem e retraimento.

Algumas pesquisas apresentam resultados que sugerem que as crianças institucionalizadas não têm alcançado os marcos de desenvolvimento. Os pesquisadores Misquiatti, Nakaguma, Brito e Olivati (2015), constataram que as crianças institucionalizadas apresentaram desempenho abaixo do esperado para sua idade, e inferior ao das crianças que vivem com suas famílias, quando comparado o seu desempenho de vocabulário (competência lexical). Segundo 
eles, os resultados deste estudo sugerem que o ambiente social das crianças, seja familiar ou institucional, não favoreceu o desenvolvimento normal da linguagem. Ainda que o ambiente familiar não tenha sido capaz de promover 0 desenvolvimento das crianças antes do acolhimento, cabe destacar a aparente falta de eficácia na promoção de desenvolvimento por parte das instituições. Compete a elas zelar pelas crianças, proteger e permitir que estas possuam uma vida de qualidade, no entanto não se percebe grandes mudanças, e as instituições não têm fornecido muito mais do que as famílias disfuncionais oferecem a estes indivíduos.

Ainda referente à linguagem, o estudo de Franco, Lopes e Lopes-Herrera (2014) mostrou que não houve diferença estatisticamente significativa entre as crianças acolhidas e as que sempre permaneceram com suas famílias, no que diz respeito às habilidades de semântica, morfologia e sintaxe. Segundo os autores, 0 acolhimento não foi um fator de risco para o desenvolvimento desta área, embora os autores concordem que crianças que vivem em instituições de acolhimento estejam mais propensas a apresentar distúrbios de linguagem. Ambas pesquisas avaliaram aspectos similares da comunicação, no entanto não obtiveram resultados equiparados. Cabe ressaltar que a segunda pesquisa, realizada por Franco e cols. (2014) não apresentou as pontuações das crianças, tornando o resultado pouco claro e duvidoso.

0 estudo realizado por Cruz e cols. (2014) demonstra que das quatro crianças acolhidas, três apresentaram alterações na área da comunicação e duas na coordenação motora fina, resolução de problemas e no estabelecimento de relações. Cabe ressaltar que apenas a coordenação motora fina estava afetada, sendo que na coordenação motora ampla, todas as crianças alcançaram um bom desempenho nas atividades. Segundo os pesquisadores, a amplitude da instituição teria favorecido o desenvolvimento da coordenação motora ampla. Cabe refletir que justamente o aspecto positivo da instituição foi responsável pelo bom desenvolvimento das crianças. Pondera-se então a importância de melhor desenvolver os demais aspectos funcionais, relacionais e estruturais ligados ao contexto institucional.

Já o estudo realizado por Guerra e Del Prette (2018) apontou que grande parte das crianças institucionalizadas apresentou déficits nas habilidades de cooperação, autocontrole e civilidade, e, além disso, se auto avaliaram negativamente, 0 que pode estar ligado a problemas de autoestima. 0 estudo de Maciel e cols. (2017) demonstrou que as crianças não tinham um entendimento completo da situação de acolhimento, onde colocavam-se como responsáveis por gerarem o encaminhamento para a instituição. Tal aspecto pode ter forte ligação com os sentimentos de depreciação e baixa autoestima apresentados no outro estudo.

\section{Considerações finais}

Os resultados desta revisão demonstram que em muitos casos a família não foi capaz de oferecer um ambiente e relações que favorecessem o desenvolvimento saudável, lesando diversos direitos destes indivíduos, em caráter físico, psicológico e social. Os artigos demonstram histórias familiares permeadas por cuidados negligentes, extrema pobreza, vulnerabilidade social e privação emocional, obrigando assim o Estado a intervir e acolher estes indivíduos.

Por outro lado, as instituições de acolhimento, que assumem o papel de zelar por estes indivíduos, acabam por estabelecer nestes ambientes relações, cuidados e funcionamentos que não tem promovido suficientemente o desen- volvimento saudável destas crianças e adolescentes. Da mesma forma que 0 contexto familiar, o contexto institucional parece perpetuar um ambiente não favorável a um bom desenvolvimento, visto que os cuidados nas instituições não têm operado de forma protetiva ou recuperadora para estes indivíduos, exercendo muitas vezes influência negativa no processo desenvolvimental.

Cabe refletir sobre as condições socioeconômicas das famílias de origem, que conforme os estudos viviam em extrema pobreza. Este é um fator que assola muitas famílias brasileiras e tende a ser gatilho para alguns tipos de privação encontradas neste meio, como a baixa nutrição, a drogadição e a falta de acesso à educação. Acredita-se que esta não seja a única variável que impacta sobre 0 ambiente familiar não favorável, mas é um problema de ordem social que chama atenção para a ineficácia das políticas públicas destinadas a evitar a fome e a miséria, no país e no mundo. Ainda que seja possível a reintegração familiar, os programas não têm sido capazes de resolver as dificuldades das famílias, onde a pobreza e a falta de acompanhamento têm sido relacionados à reinstitucionalização de muitas crianças e adolescentes (Paiva \& cols., 2019).

Corroborando com Sá e cols. (2017), entende-se que é chegada a hora da prática da caridade ser substituída por uma atenção profissional, onde a manutenção da sobrevivência deverá dar lugar a uma prática efetivamente protetiva. Mais do que apenas cessar os prejuízos impostos pelas péssimas condições familiares, 0 ambiente de acolhimento institucional deveria favorecer o desenvolvimento dos indivíduos, com atuação capacitada que proteja, promova e estimule o crescimento saudável, feliz e digno.

Ainda que os objetivos desta pesquisa tenham sido atingidos, é importante ressaltar que esta revisão apresentou al gumas limitações como pesquisas com amostras pequenas e poucos estudos de caso controle. Os resultados encontrados podem ser úteis ao planejamento de programas e políticas públicas voltados tanto às famílias que tiveram seus filhos acolhidos, como para o desenvolvimento de ações voltadas às instituições e equipes responsáveis pelo cuidado destas crianças e adolescentes. A psicologia, neste sentido, pode e deve agir como forte aliada na análise e planejamento de tais ações, através de uma visão ampla do ser humano e dos processos desenvolvimentais.

\section{Referências}

Avoglia, H. R. C., Silva, A. M. da, \& Mattos, P. M. (2012). Educador social: imagem e relações com crianças em situação de acolhimento institucional. Rev. Mal-Estar Subj, 12(1), 265-292. Disponível: $<$ http://pepsic.bvsalud.org/scielo. php?script=sci_arttext\&pi$d=\$ 1518-61482012000100010 \&|n g=p t \& t| n g=p t .>$.

Bianchin, L. F., \& Gomes, K. M. (2018). 0 desenvolvimento da empatia e vínculo afetivo em crianças e adolescentes abrigados. Revista de Iniciação Científica, 16(1), 41-54. Disponível: < http://periodicos.unesc.net/iniciacaocientifica/article/view/4271/4043>.

Both, L. M., \& Benetti, S. P. da C. (2017). As representações parentais em crianças institucionalizadas filhos de usuária de crack. Estudos e Pesquisas em Psicologia, 17(1), 277-305. D01:10.12957/epp.2017.34999.

Brasil (1990). Lei Federal n. 8069, de 13 de julho de 1990. ECA_Estatuto da Criança e do Adolescente.

Brasil (2006). Presidência da República. Ministério Do Desenvolvimento Social E Combate À Fome. Secretaria Especial Dos Direitos Humanos. Conselho Nacional de Assistência Social. Plano nacional de promoção, proteção e defesa do direito de crianças e adolescentes à convivência familiar e comunitária. Brasília/DF, dezembro. 
Cavalcante, L. I. C., Magalhães, C. M. C., \& Reis, D. C. (2014). Análise comparativa do perfil de crianças em acolhimento institucional nos anos de 2004 e 2009. Psico, 45(1), 90-99. D0l: https://doi.org/10.15448/19808623.2014.1.13180.

Corrêa, L. da S., \& Cavalcante, L. I. C. (2013). Shelter educators: conceptions on development and care practices in play situation. Journal of Human Growth and Development, 23 (3), 309-317. Disponível: < http://pepsic.bvsalud.org/scielo.p hp?script=sci_arttext\&pi$d=$ S0104-12822013000300009\&lng=pt\&tlng=en.>.

Cruz, E. J. S. da, Dias, G. B., \& Pedroso, J. da S. (2014). Estudo do "Ages and Stages Questionnaires" com cuidadores de crianças institucionalizadas. Psico-USF, 19(3), 411-420. D0l:10.1590/1413-82712014019003004.

Dias, G. B., Pedroso, J. da S., \& Santos, A. C. S. L. (2015). Avaliação de Desenvolvimento de Bebês em Acolhimento Institucional com Ages and Stages Questionnaires. Mudanças - Psicologia da Saúde, 23(2), 1-7. D0l: https:// doi.org/10.15603/2176-1019/mud.v23n2p1-7.

Franco, E. C., Lopes, A. C., Lopes-Herrera, S. A. (2014). Linguagem receptiva e expressiva de crianças institucionalizadas. Revista (EFAC, 16(6), 18371841. D0l:10.1590/1982-021620149713.

Golin, G., \& Benetti, S. P. da C. (2013). Acolhimento Precoce e o Vínculo na Institucionalização. Psicologia: Teoria e Pesquisa, 29 (3), 241-248. Disponível: $<$ https://periodicos.unb.br/index.php/revistaptp/article/view/17611>.

Gontijo, D. T., Buiati, P. C., Santos, R. L. dos, \& Ferreira, A. T. D. (2012). Fatores relacionados à institucionalização de crianças e adolescentes acolhidos na comarca de Uberaba - MG. Revista Brasileira Em Promoção Da Saúde, 25(2), 139-150. Disponível: < https://www.redalyc.org/articulo. oa?id $=40823359003>$.

Guerra, L. L., \& Del Prette, Z. P. (2018). Habilidades sociais educativas de cuidadores de crianças institucionalizadas. Arquivos Brasileiros de Psicologia, 70 (3), 98-112. Disponível: <http://pepsic.bvsalud.org/scielo.php?scrip$\mathrm{t}=$ sci_arttext\&pid=S1809-52672018000300008\&lng=pt\&tlng=pt. $>$.

Heumann, S., \& Cavalcante, L. I. C. (2018). Rotinas de crianças eadolescentes em acolhimento institucional: estudo descritivo. Arquivos Brasileiros de Psicologia, 70 (2), 22-37. Disponível < http://pepsic.bvsalud.org/s cielo.php?script $=$ sci_arttext\&pid $=\$ 1809=52672018000200003-\& \operatorname{lng}=$ pt\&tIng$p t>$.

Maciel, R. de F.M., Teodoro, M. C., Alves, J. R., Ribeiro, L. M., \& Serralha, L. G. Q.C. A. (2017). Crianças à espera de adoção ou em medida protetiva: a inclusão escolar. Rev. SPAGESP, 18 (1), 63-79. Disponível: < http://pepsic.bvsalud. org/scielo.php?script=sci_arttext\&pid=\$167729702017000100006\&l$\mathrm{ng}=\mathrm{pt \& t}$ tlng=pt. $>$.

Misquiatti, A. R. N., Nakaguma, P. G., Brito, M. C., \& Olivati, A. G. (2015). Desempenho de vocabulário em crianças pré-escolares institucionalizadas. Revista (EFAC, 17 (3), 783-791. Disponível: < https://repositor io.unesp. br/han dle/11449/158137>.

Paiva, I. L. de, Moreira, T. A. S., \& Lima, A. de M. (2019). Acolhimento Institucional: famílias de origem e a reinstitucionalização. Revista Direito e Práxis, 10(2), 1405-1429. DOl: 10.1590/2179-8966/2019/40414.

Pereira, M., Soares, I., Dias, P., Silva, J., Marques, S., \& Baptista, J. (2010). Desenvolvimento, psicopatologia e apego: estudo exploratório com crianças institucionalizadas e suas cuidadoras. Psicologia: Reflexão e Crítica, 23 (2), 222-231. Disponível: <https://doi.org/10.1590/S0102$79722010000200004>$.

Sá, C. dos S. C. de, Jurdi, A. P. S., \& Panciera, S. D. P. (2017). Desenvolvimento infantil e 0 ambiente institucional - experiência com bebês abrigados. Revista Ciência Em Extensão, 13(1), 102-111. Disponível: <https://ojs. unesp.br/index. php/revista_proex/article/view/1527>.

Silva, T. S. R. e, Magalhães, C. M. C., \& Cavalcante, L. I. C. (2014). Interações entre avós e netos em instituição de acolhimento infantil. Arquivos Brasileiros de Psicologia, 66 (1), 49-60. Disponível: <https://www.redalyc. org/articulo.0a?id $=229030926004>$.
Silveira, A. C., Costa, S. C. M. F., Pinho, C. P. S., \& Santana, S. C. S. (2016). Condição nutricional de crianças admitidas em uma instituição de acolhimento. Revista Brasileira Em Promoção Da Saúde, 29(1), 5-13. D0l: https://doi. org/10.5020/18061230.2016.p5.

Siqueira, A. C., \& Dell'Aglio, D. D. (2010). Crianças e adolescentes institucionalizados: desempenho escolar, satisfação de vida e rede de apoio social. Psicologia: Teoria e Pesquisa, 26(3), 407-415. D0l: https://doi. org/10.1590/S0102-37722010000300003.

Tomás, D. N., \& Vectore, C. (2012). Perfil mediacional de mães sociais que atuam em instituições de acolhimento. Psicologia: Ciência e Profissão, 32 (3), 576-D01:587. https://doi.org/10.1590/S1414-98932012000300005. Vasconcellos, F. P. A., \& Koehler, S. M. F. (2011). Convívio familiar e desenvolvimento psicossocial da criança. Revista CNPq. 12017-12027. Disponível: $<$ https://educere.bruc.com.br/CD2011/pdf/4645_2536.pdf>.

Zappe, J. G., \& Dell'Aglio, D. D. (2016). Risco e Proteção no Desenvolvimento de Adolescentes que Vivem em Diferentes Contextos: Família e Institucionalização. Revista Colombiana de Psicologia, 25 (2), 289-305. D0l: http:// dx.doi.org/10.15446/rcp.v25n2.51256. 